\title{
Flow Stress and Mathematical Model for DRX Evolution of Semi-continuous Cast AZ80 Alloy During Hot Deformation
}

\author{
LIANG Haicheng ${ }^{1, \mathrm{a}}$, FENG Lijun ${ }^{2, \mathrm{~b}}$ and WANG Zhongtang ${ }^{1, \mathrm{c}}$ \\ 1. School of Materials Science and Engineering, Shenyang Ligong University, Shenyang, China \\ 2.Technical Department, Qiqihar Huaan Special Container Co., LTD, Qiqihar, China

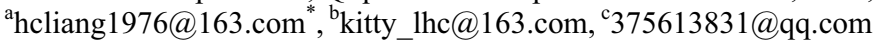

\begin{abstract}
Using electromagnetic fields application ways, AZ80 magnesium alloy is semi-continuously cast into billets with diameter of $165 \mathrm{~mm}$. And the dynamic recrystallization (DRX) evolution of the semi-continuous cast AZ80 magnesium alloy during hot compression has been experimentally studied on Gleeble 2000 thermal-mechanical simulator, at temperatures from 260 to $410^{\circ} \mathrm{C}$ and strain rates from 0.001 to $10 \mathrm{~s}-1$. It is found that the chief microstructure evolution is dynamic recrystallization, and the effect of deformation process parameters on DRX evolution is analyzed. The mathematical models including critical recrystallization model, kinetics model and grain size model of DRX are established and the results show good agreement between experiments and the models.
\end{abstract}

\section{Introduction}

In recent years, the structural applications of magnesium alloys in aerospace and automobile industries are increasing progressively. This is not only because of their low densities but also because of their excellent properties such as heat-dissipation, damping, electro-magnetic shielding and recycling [1-3]. The volume of wrought magnesium products is considerably less than that of casting products. However, wrought magnesium alloys may have more development potential with the higher strength, improved ductility and other mechanical property advantages. As a result, plastic processing technology of the magnesium alloy attracts more and more attention.

One of the key factors decided the final performance organization is internal microstructure evolution in plastic forming process. With development of computer simulation technology, it is possible to accurately predict microstructure and mechanical properties of plastic forming products. But, for simulating the process of metal deformation and forecasting microstructure evolution, it is necessary to establish complete and accurate microstructure evolution model [4]. Hence, it's of important significance to establish the quantitative relationship between thermal deformation parameters and

\footnotetext{
* Corresponding author:hcliang1976@163.com
} 
microstructure for predicting microstructure evolution in the plastic deformation process and reasonably drawning up forming process.

Research on deformation behavior and DRX of magnesium alloys has made a lot of progress in the world[5-12]. But, it is necessary to deeply discuss the relationship between deformation parameters and evolution in order to forecast microstructure evolution of forming products.

One of the most common ways of hot forming magnesium alloy billets is semi-continuous cast magnesium alloy ingot. Investigations on the flow stress and microstructure of magnesium alloys at different forming temperatures and strain rates have been an important subject in wrought magnesium alloys forming[13-15]. In this paper the flow stress and the relationship of DRX, strain rate and temperature of semi-continuous cast AZ80 magnesium alloy by hot compression at different forming temperatures and strain rates were studied, serving as the theoretical base for working out the plastic manufacturing parameters of magnesium alloy.

\section{Experimental Procedures}

The composition of AZ80 ingot (wt.\%) is as follows: Al 8.6, $\mathrm{Zn} \mathrm{0.45,} \mathrm{Mn} \mathrm{0.15,} \mathrm{Si}$ $0.03, \mathrm{Cu} \leq 0.01, \mathrm{Ni} \leq 0.001, \mathrm{Fe} \leq 0.005$,impurity $\leq 0.3$, and $\mathrm{Mg}$ balance. Cylindrical specimens with diameter of $8 \mathrm{~mm}$ and height of $15 \mathrm{~mm}$ were used for compression testing. In addition, grooves were provided on the load bearing surfaces so that effective lubrication was ensured during compression. The hot compressive tests were conducted on Gleeble-2000 thermal simulator testing machine. Specimens were heated to test temperatures, soaked for $5 \mathrm{~min}$ for equilibration. The specimens were compressed at the temperature and strain rate ranges of $260 \sim 410^{\circ} \mathrm{C}$ and $0.001 \sim 10 \mathrm{~s}^{-1}$, followed by water quenching. Photomicrograps were taken with metallographic microscope.

\section{Results and Discussion}

\subsection{Microstructures of semi-continuous cast AZ80}

Microstructures of semi-continuous cast AZ80 is shown in Fig.1. From Fig.1, it can be seen that the casting structure of AZ80 alloy is composed of gray $\alpha-\mathrm{Mg}$ solid solution and black $\beta-\mathrm{Mg} 17 \mathrm{Al1} 2$ distributed networks in the interface. Diffusion process of solute was suppressed due to the magnetic field, so the content of $\mathrm{Al}$ and $\mathrm{Zn}$ solute elements has actually increased inside the $\alpha-\mathrm{Mg}$ grain.

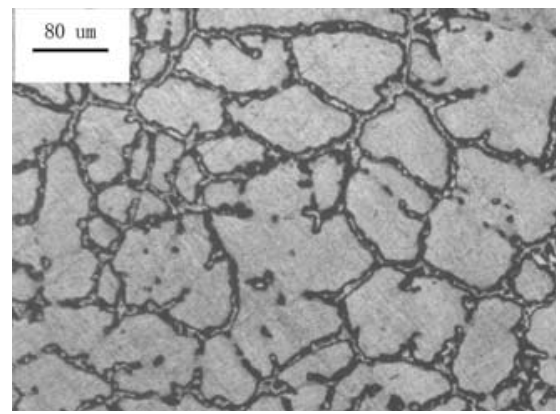

Fig.1 Microstructures of semi-continuous cast AZ80 


\subsection{Flow stress behavior}

The stress-strain curves of the AZ80 magnesium alloy at different strain rates and different deformation temperatures is shown in Fig.2. It can be founded that the general characteristics of the flow stress curves are similar at all deformation conditions and such flow stress behaviors are typical characteristics of hot working that is accompanied by dynamic recrystallization(DRX)[16]. The flow stress increases to a peak because of work hardening and then decreases to a steady state. The value gap between the peak stress and the flow stress in stable stage decreases with decreasing strain rate and the peak stress is almost equal to the flow stress in stable stage at strain rate of $0.001 \mathrm{~s}-1$. The peak stress increases with increasing strain rate at the same temperature and decreases with increasing temperature at the same strain rate. The true strain value of steady state increases with increasing strain rate and decreasing temperature.

\subsection{Microstructural development}

\section{Influence of strain rates}

Microstructural evolution of the AZ80 magnesium alloy under different strain rates is shown when temperature was $310^{\circ} \mathrm{C}$ in Fig.3.

It can be founded that DRX becomes more sufficiency and the DRX grain size becomes thinner with increasing strain rate at the same temperature. This is because that nucleating of recrystallization is a course of controlling defective density, and DRX can be enabled only when dislocation density reaches critical value. So rapid deformation is beneficial to accumulating of dislocation and accelerates enabling of DRX. In addition, decreasing strain rate supplies sufficient time for crystal boundary migration and prolongs time of recrystallized grains growth. Therefore rapid deformation is beneficial to grain refining. However, excessively high strain rate would lead to accumulating dislocation inadequately before the deformation terminate, and appear chaotic texture composed of twin, coarse grain and duplex grain structure owing to higher deformation temperature and higher strain rate. 

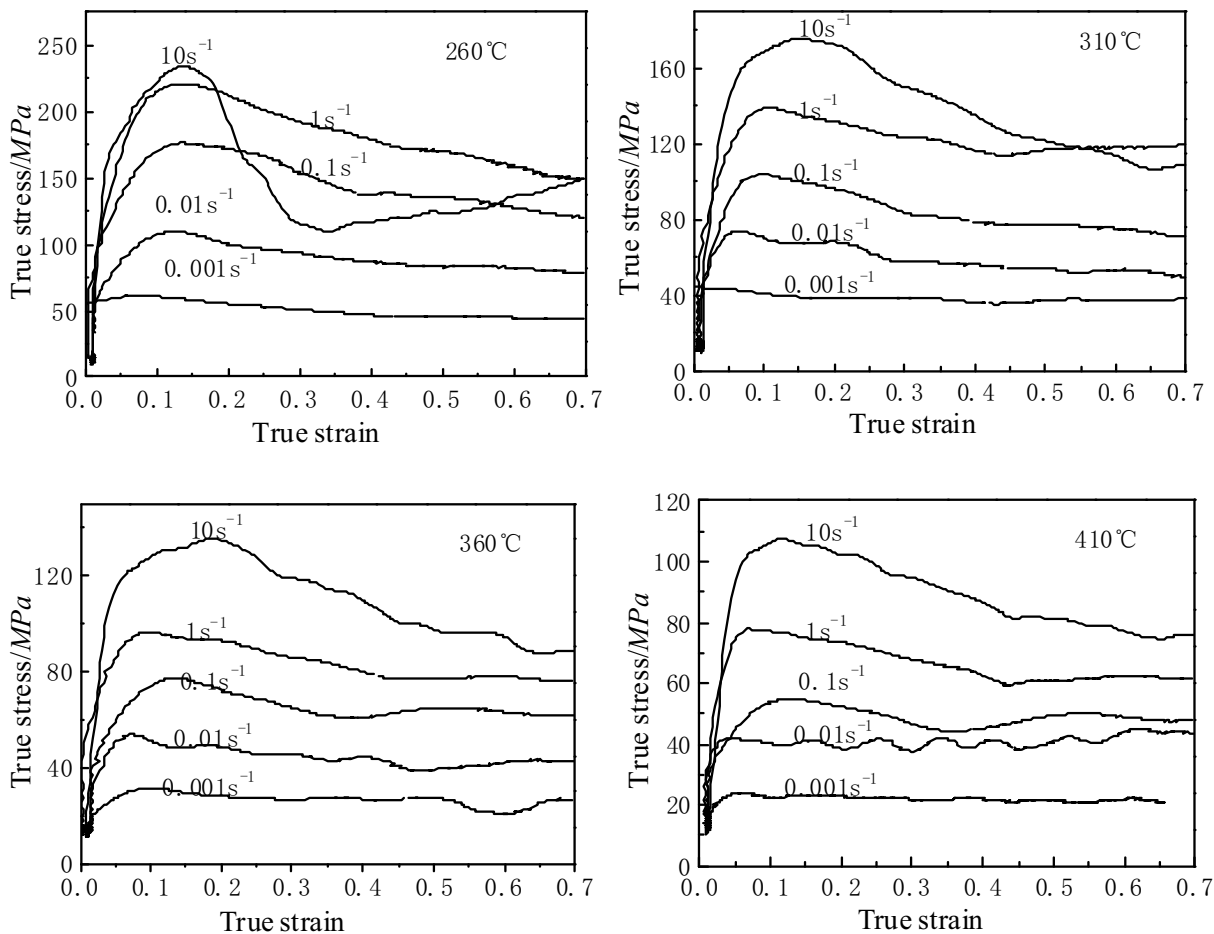

Fig.2 True stress-true strain curves at different conditions

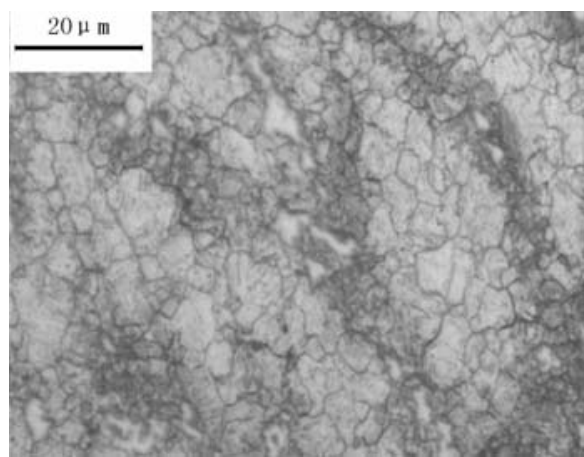

(a) $0.01 \mathrm{~s}^{-1}$

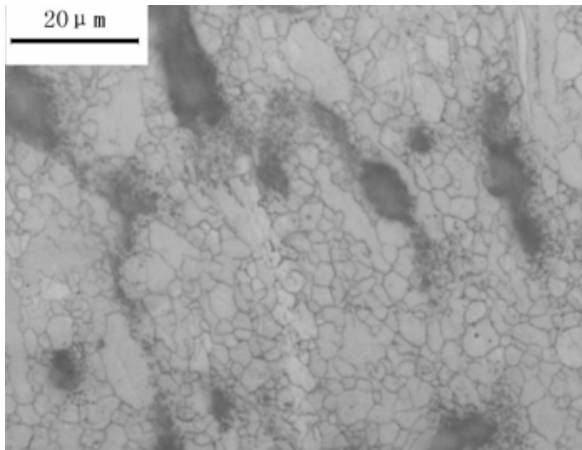

(c) $1 \mathrm{~s}^{-1}$

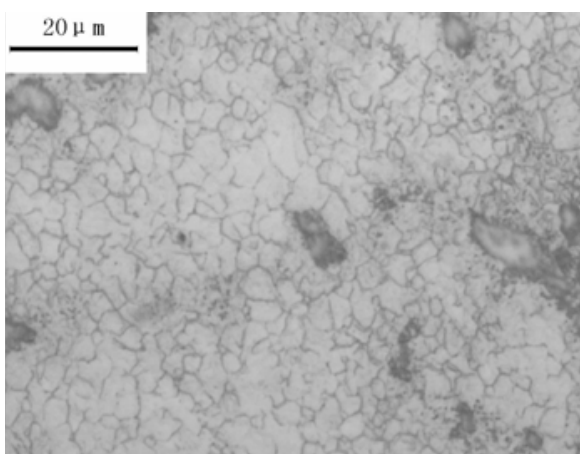

(b) $0.1 \mathrm{~s}^{-1}$

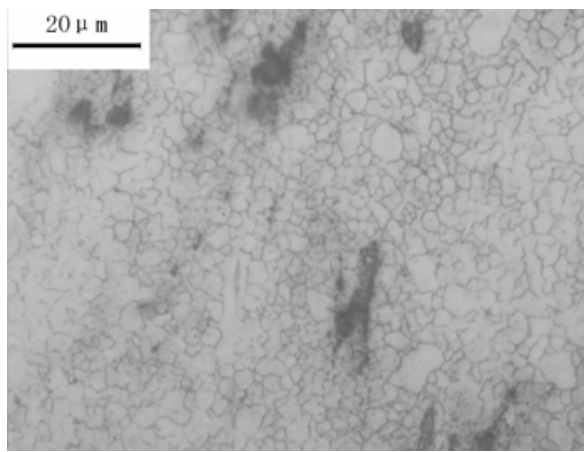

(d) $10 \mathrm{~s}^{-1}$

Fig. 3 Microstructure under different strain rates 


\section{Influence of deformation temperatures}

Microstructural evolution of the AZ80 magnesium alloy under different temperatures is shown when strain rate is $0.01 \mathrm{~s}-1$ in Fig.4. The results show that DRX can occur under different deformation temperatures. Degree of DRX increases with increasing deformation temperature, and the recrystallized grains become growing. At a high temperature of $410^{\circ} \mathrm{C}$ DRX grains are much larger and reach more than $10 \mu \mathrm{m}$.

As explained in the description above, on the one hand, increasing deformation temperature is conducive to occurrence of DRX. On the other hand, above $260^{\circ} \mathrm{C}$, DRX finished completely at different strain rates, internal distortion of grain is basically eliminated and dislocation density is significantly lower. Nucleation rate of secondary recrystallization has decreased significantly at high temperature, and rate of grain growth has not changed much owing to controlled by heat diffusion process, these lead to coarsening of grain size.

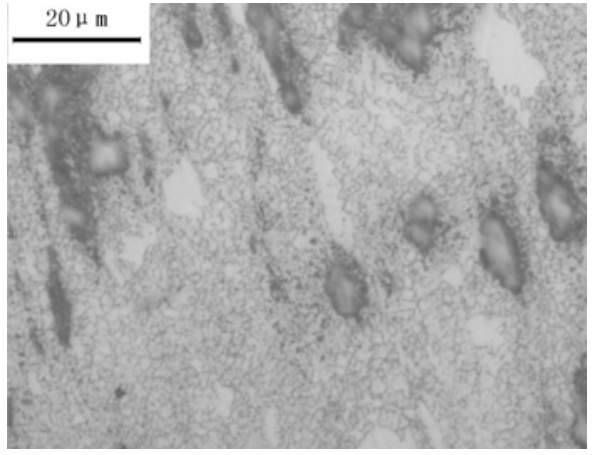

(a) $260^{\circ} \mathrm{C}$

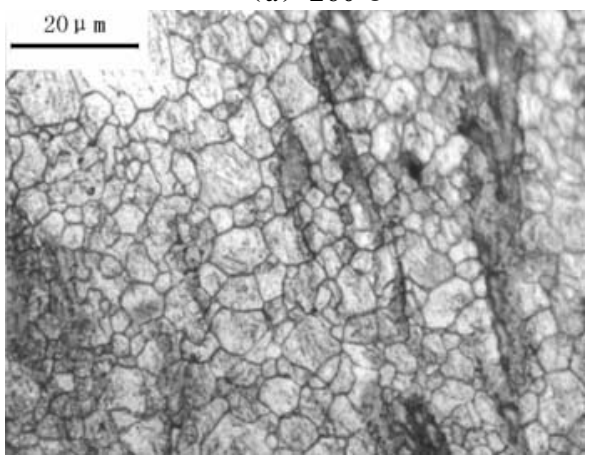

(c) $360^{\circ} \mathrm{C}$

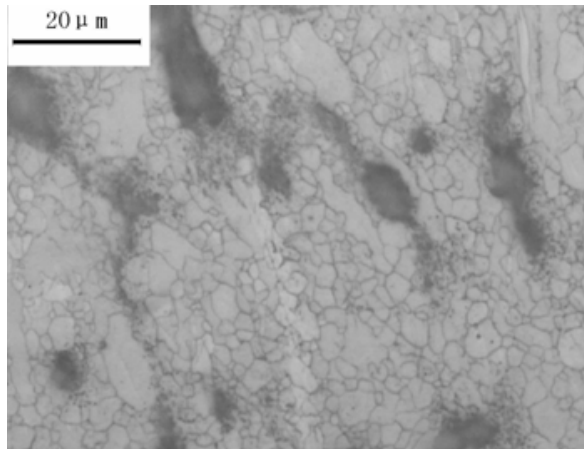

(b) $310^{\circ} \mathrm{C}$

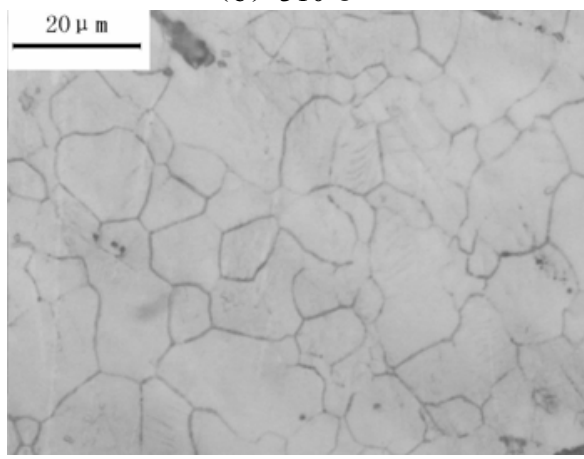

(d) $410^{\circ} \mathrm{C}$

Fig.4 Microstructure under different deformation temperatures

\subsection{Mathematical Model for DRX Evolution}

In recent years, research on simulating microstructure evolution in the plastic deformation process has been increasing gradually. The vast majority of material models are much of a muchness as the empirical equation established by R.Kopp[17]. In this paper, DRX and equation of grain growth of AZ80 hot deformation process are studied with the model established by R.Kopp.

\section{Critical recrystallization model}

First of all, it needs to determine three strain values, $\varepsilon_{p}, \varepsilon_{c}$ and $\varepsilon_{s}$, in order to establish mathematical model for DRX. 


$$
\begin{array}{r}
\varepsilon_{p}=k_{1} Z^{n_{1}} \\
(1) \\
\varepsilon_{c}=k_{2} \varepsilon_{p} \\
\varepsilon_{s}=k_{3} Z^{n_{2}} \\
Z \quad=\quad \varepsilon \& \mathrm{e} \times \mathrm{p}\left(\frac{Q}{R}\right)^{(3)}
\end{array}
$$

Where $\varepsilon_{p}$ is strain correspond with the peak stress, $\varepsilon_{c}$ is critical strain of DRX, $\varepsilon_{s}$ is strain of complete dynamic recrystallization, $k_{i}$ and $n_{i}$ is material constants, $\mathrm{Z}$ is the Zener-Hollomon parameter, $T$ is temperature, $R$ is the gas constant, $Q$ is the hot deformation activation energy.

$\varepsilon_{p}$ and $\varepsilon_{s}$ can be measured through the flow stress curve, and $\varepsilon_{c}$ can be determined by Eq.(2). $\quad k_{2}$ was 0.75 according to the literature[18]. So the model coefficients of Eq. (1) and Eq. (3) can be determined. It is found that the hot deformation activation energy $(Q)$ is $224 \mathrm{~kJ} / \mathrm{mol}$ through texting and calculating. And through taken logarithm and calculated partial derivative to Eq. (1), $n_{1}$ can be expressed in the following form

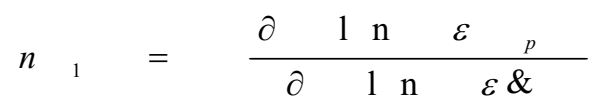

Regression analysis is used to determine the value of $n_{1}$, then $k_{1}$ can be expressed in the following form

$$
k_{1}=\frac{\varepsilon_{p}}{Z^{n_{1}}}
$$

The values of $n_{2}$ and $k_{3}$ can be got by using such methods. According to calculating, $\varepsilon_{p}, \varepsilon_{c}$ and $\varepsilon_{s}$ are given as

$$
\begin{aligned}
& \varepsilon_{p}=2.235 \times 10^{-3} Z^{0.083} \\
& \varepsilon_{c}=0.75 \varepsilon_{p} \\
& \varepsilon_{s}=0.0027 Z^{0.118} \\
& Z=\varepsilon \& \mathrm{e} \times \mathrm{p}\left(\begin{array}{cccccc}
2 & 2 & 4 & 0 & 0 & 0 \\
\hline R & T
\end{array}\right)
\end{aligned}
$$

\section{Kinetics model for DRX evolution}

Volume fraction model of DRX proposed by R.Kopp is given as

$$
X_{D R X}=1-\exp \left[-k_{4}\left(\frac{\varepsilon-\varepsilon_{c}}{\varepsilon_{s}-\varepsilon_{c}}\right)^{n_{3}}\right]
$$


Where $X_{D R X}$ is volume percent of DRX.

$X_{D R X}$ can be determined from the stress-strain curves of magnesium alloy. The relations of volume fraction model of DRX and stress parameters can be expressed in the following form[19]

$$
X_{D R X}=\frac{\sigma_{\mathrm{c}}-\sigma}{\sigma_{\mathrm{c}}-\sigma_{\mathrm{s}}} \quad\left(\varepsilon_{\mathrm{c}}<\varepsilon<\varepsilon_{\mathrm{s}}\right)
$$

Where $\sigma_{\mathrm{c}}$ is the stress correspond with the critical strain, $\sigma_{\mathrm{s}}$ is the stress that DRX finished completely.

$X_{D R X}$ can be determined at different deformation conditions by Eq.(12), and combined with regression analysis for Eq.(11), the values of $n_{3}$ and $k_{4}$ can are given as

$$
X_{D R X}=1-\exp \left[-1.803\left(\frac{\varepsilon-\varepsilon_{c}}{\varepsilon_{s}-\varepsilon_{c}}\right)^{2.231}\right]
$$

\section{Grain size model of DRX}

The effect of crystallite dimension on room temperature and high temperature properties of forgings is significant. Hense, change rule of grain size in hot-working process has been studied for long periods and numerous studies show that the relations of grain size of recrystallization and $\mathrm{Z}$ parameter can be expressed in the following form

$$
\begin{array}{r}
d_{D R X}=k_{5} Z^{n_{4}} \\
\bar{d}=\left(1-X_{D R X}\right) d_{0}+X_{D R X} d_{D R X}^{(14}
\end{array}
$$

Where $d_{D R X}$ is grain size of DRX, $\bar{d}$ is average grain size, $d_{0}$ is initial grain size. $d_{D R X}$ is measured by metallographic examination. And through taken logarithm and calculated partial derivative to Eq. (14), $n_{4}$ and $k_{5}$ can be expressed in the following form

$$
\begin{array}{r}
n_{4}=\frac{\partial 1 \mathrm{n} d{ }_{D R X}}{\partial 1 \mathrm{n} \varepsilon \&} \\
k_{5}=\frac{d_{D R X}}{Z^{n_{4}}}
\end{array}
$$

Regression analysis is used to determine the value of $n_{4}$ and $k_{5}$.

At last, under temperatures from 260 to $410^{\circ} \mathrm{C}$ and equivalent strain rates 0.001 to $10 \mathrm{~s}^{-1}$, grain size model of AZ80 magnesium alloy can be given as

$$
d_{D R X}=402.9 Z^{-0.113}
$$

\section{Model verification}

Initial grain size of the AZ80 magnesium alloy is $60 \mu \mathrm{m}$, and average grain size of $\alpha$ phase can be calculated by Eq. (15). Comparison between calculated and measured values of average grain size of DRX is shown in Fig.6, and the average error is $7.3 \%$. It can be concluded from Fig.5 that the microstructure models could effectively depict the microstructure evolution law of AZ80 magnesium alloy at temperatures from 260 to $410^{\circ} \mathrm{C}$ and equivalent strain rates 0.001 to $10 \mathrm{~s}^{-1}$. 


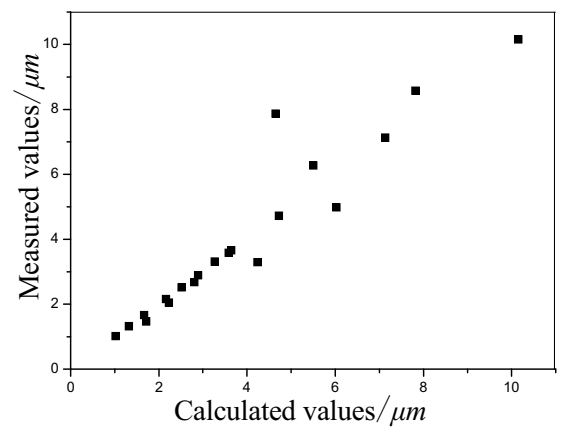

Fig. 5 Comparison between calculated and measured values

\section{Conclusions}

(1) Semi-continuously casting AZ80 magnesium alloy used electromagnetic fields application ways has fine grain and better plastic forming properties

(2)The true stress-true strain curves of AZ80 magnesium alloy indicates that the deformation behaviour of the alloy depends significantly on temperatures and equivalent strain rates. The flow stress of alloy decreases with increasing temperatures and decreasing strain rates.

(3) Microstructure evolution behavior of AZ80 magnesium alloy in thermal deformation process is mainly DRX, and the deformation process parameters have significant effect on recrystallization.

(4) The mathematical models of DRX are got in the following form

$$
\begin{gathered}
\varepsilon_{p}=2.235 \times 10^{-3} Z^{0.083} \\
\varepsilon_{c}=0.168 \times 10^{-2} Z^{0.083} \\
\varepsilon_{s}=0.0027 Z^{0.118} \\
Z=\varepsilon \& \mathrm{exp}\left(\frac{224000}{R T}\right) \\
X_{D R X}=1-\exp \left[-1.803\left(\frac{\varepsilon-\varepsilon_{c}}{\varepsilon_{s}-\varepsilon_{c}}\right)^{2.231}\right] \\
d_{D R X}=402.9 Z^{-0.113}{ }^{2}
\end{gathered}
$$

\section{Acknowledgment}

The study was financially supported by National Science Foundation of China (51575366) and Open Fund of Liaoning Province Key Laboratory of Advanced Manufacturing Technology on Metal Materials, Shenyang Ligong University. 


\section{References}

1. Diem W. Magnesium in Different Application[J]. Auto Techonology,2001.1:40-41.

2. Kamado S,Koike J,Kondoh K et al. Magnesium Research Trend in Japan [J]. Materials Science Forum,2003.419-422:21-34.

3. Liu Chuang, Li Yusheng, Ma Zhiyi, Feng Zhijun, Zhai Hu, and Zhang Yalong. Effects of $\mathrm{La} 2(\mathrm{CO} 3) 3$ on microstructure and mechanical properties of ZM-5 magnesium alloy[J]. China Foundry,2011,7 (3):248-252.

4. Wang Ruining, Xi Zhengping, Zhao Yongqing, Qi Yunlian.Hot deformation and processing maps of titanium matrix composite[J]. Trans Nonferrous Met Soc China,2007,17(3) 541-545. (in chinese)

5. Ma Zhixin, Zhang Jiazhen, Li Defu, Zhang Kui. Study on flow stress of Mg-Gd-Y-Zr magnesium alloy during hot-compression[J]. Hot Working Technology, 2007, 36(22):26-29. (in chinese)

6. Xiong Chuangxian, Zhang Xinming, Deng Yunlai. Effects of cryogenic treatment on mechanical properties of extruded Mg-Gd-Y- $\mathrm{Zr}(\mathrm{Mn})$ alloys[J]. Journal of Central South University of Technology, 2007(3): 305-309. (in chinese)

7. Barnett M R. Recrystallization during and following hot working magnesium alloy AZ31 [J]. Mater Sci Forum,2003.419(4):503-508.

8. Barnett M R.Influence of deform ation conditions and texture on the high temperature flow stress of magnesium AZ31[J]. Journal of Light Metals, 2001.1(3):167- 177.

9. Liu Chuming, Liu Zijuan, Zhu Xiurong, Zhou Haitao. Research and development progress of dynamic recrystallization in pure magnesium and its alloys[J]. The Chinese Journal of Nonferrous Metals, 2006. 1:1-12. (in chinese)

10. Perez-prado M T, Del Valle J A, Contreras J M, Ruano O A. Microstructural evolution during large strain hot rolling of an AM60 Mg alloy[J]. Scripta Materialia, 2004, 50:661-665.

11. Galiyev A, Kaibyshev R, Sakai T. Continuous dynamic recrystallization in magnesium alloy[J]. Materials Science Forum, 2003, 419-422: 509-514.

12. Yang Xuyue, Miura H, Sakai T. Dynamic evolution of new grains in magnesium alloy during hot deformation[J]. Materials Transactions, 2003, 44: 197-203.

13. Mukai T. Experimental study of the mechanical properties at elevated temperatures in commercial Mg2Al2Zn alloys for superplastic forming [J]. Materials Science Forum ,2000,171-174:337-342.

14. Watanable H. Superplastic behavior in commercial wrough magnesium alloys[J]. Materials Science Forum,2000,350-351: 171-176.

15. New E J . Magnesium rolled products for automobile applications [A] . Proceedings of the Second Irsraeli International Conference on Magnesium Science and Technology[C]. 2000, 19-26.

16. Xiao pan, Liu Tianmo. Study on hot compression deformation simulation of AZ61B magnesium alloy[J]. Ordnance Material Science and Engineering, 2006.7(4):22-25. (in chinese)

17. K.Karhausen and R.Kopp,Model for Integrated Process and Microstructure Simulation in hot Forming [J],Steel Research,1992.63:247-266. (in chinese)

18. Dou Xiaofeng, Zhao Hui, Lu Shouli. Simulating Evolution of Microstructure during Metal Hot Forming $[\mathrm{J}]$. Journal of University of Science and Technology Beijing, 1996.18(6): 53-54. (in chinese)

19. Dou Xiaofeng, Lu Shouli, Zhao Hui. Establishment of the Dynamic Recrystallization Model Q235[J]. Journal of University of Science and Technology Beijing, 1998.20(5):467-468.(in chinese) 